\title{
Pain Signals are Predominantly Imperative
}

\author{
Manolo Martínez \\ Departament of Philosophy, Universitat Autònoma de Barcelona \\ Logos Research Group in Analytic Philosophy \\ Colin Klein \\ Department of Philosophy, Macquarie University

\begin{abstract}
Recent work on signaling has mostly focused on communication between organisms. The Lewis-Skyrms framework should be equally applicable to intra-organismic signaling. We present a Lewis-Skyrms signaling-game model of painful signaling, and use it to argue that the content of pain is predominantly imperative. We address several objections to the account, concluding that our model gives a productive framework within which to consider internal signaling.
\end{abstract}

\section{Introduction}

One prominent research agenda in the philosophy of mind aims at explicating the dependence of sensory phenomenology on biological goings-on. How can neurophysiological processes possibly constitute the subjective, qualitative, ineffable, 
apparently irreducible phenomenology associated with a perception as of a red patch or the pain caused by an ingrown nail? ${ }^{1}$

Many theorists advocate the use of intentional (content-based) notions as a way to bridge the gap between phenomenology and biology. In this intentionalist program, phenomenology depends upon intentional properties of mental states. The intentional content of mental states, in their turn, depend upon the biological properties of what instantiates them (or other appropriately related states) (Dretske, 1997; Tye, 1995, among many others). The intentionalist program thus provides a two-step naturalization of phenomenology.

Affective (pleasant or unpleasant) phenomenology, and painful phenomenology in particular, is typically taken to present a problem for the intentionalist program (Aydede, 2006; Block, 2006). We have recently argued (Klein, 2007, 2015; Martínez, 2011; Martínez, 2015; Klein and Martínez, forthcoming) in favor of imperativism, the thesis that these difficulties are avoided if the phenomenal character of pain depends on imperative (rather than indicative) content. According to imperativism, pain gives the experiential equivalent of a command to its subject. For example, the content of the pain of an ingrown nail would be, roughly,

Protect your nail!

The effect of such an imperative, under ordinary circumstances, would be that the subject protected their nail until the problem resolved itself. We believe imperativism has many advantages. We will not discuss them here. Instead, we would like to focus on one shortcoming of philosophical treatments of imperativism, and of intentionalism in general. The foregoing introductory paragraphs are typical of such treatments, in that the proposal for the content of

\footnotetext{
${ }^{1}$ See Chalmers (1996); McGinn (1989); Tye (1995) for compelling statements of the problem.
} 
ingrown-nail pain is given by means of a sentence in natural language - usually a simple English sentence. This undoubtedly helps the casual onlooker find out quickly what the theory is all about (and, if it seems wildly implausible, to move on quickly), but it is ultimately unsatisfactory if taken literally. Sensations and perceptions are not linguistic entities, even if they are contentful. It is also unclear just which of the contents that can be expressed in English can be carried by these other vehicles. It is similarly unclear how that would work if so.

We can improve on linguistic paraphrases, we suggest, by recasting imperativism in terms of more explicit models of content. In particular, in this paper we present a Lewis-Skyrms signaling model of those pains that can be produced both in the absence and the presence of an inflammatory process. This will be, therefore, a model of all non-neuropathic pains (i.e. most familiar pains) (Abrahamsen et al., 2008). Abusing language for the sake of brevity, we will refer to all such pains as inflammatory, but note that the model applies to every token pain which could have occurred in the presence of inflammation, regardless of whether it actually did.

Lewis-Skyrms models are explicit about what counts as the imperative and indicative contents of a signal. We will use these specifications to show that, in such models, inflammatory pain is indeed predominantly imperative. ${ }^{2}$. This, it will turn out, is because the causes of pain are heterogenous (and the same messages need to be reused in different contexts to signal different states) while the acts that pains provoke are comparatively unified. We expect two results

\footnotetext{
${ }^{2}$ Such explicitness and clarity, while invaluable for our current exploratory purposes, come at a price: many problems that other psychosemantic theories, such as teleosemantics (Millikan, 1984; Papineau, 1987), tackle, are simply brushed aside in the Lewis-Skyrms models we will be relying on. For one important example among many, indeterminacy problems (Fodor, 1990) do not arise in the first place.

This is, we submit, as it should be: adding in the machinery necessary to deal with these issues would complicate the discussion, with no clear explanatory payback in the present context. In any event, we expect that the main lessons to be drawn from the present discussion will carry over to more complex accounts of mental content.
} 
from this game-theoretic reformulation of the imperativist insight.

First, we offer the resulting Lewis-Skyrms imperativism as a way of elaborating on the suggestion (made by Huttegger, 2007; Matthen, 2005, p. 240, among others) that signaling games could be fruitfully deployed in the explication of internal signaling. If we are right, inflammatory pain is a case of predominantly imperative signaling, and Lewis-Skyrms models can be used to show this.

By fleshing out the Lewis-Skyrms model, we thus provide a principled way to approach questions about the content of sensory states. As imperativists, of course, we believe that all pains (including neuropathic ones), will end up on the imperative side of the ledger. In order to make the structure of the overall theory clear, however, we will confine ourselves to a telling set of cases.

Second, elaborating the Lewis-Skyrms model will provide grounds for resisting a popular reaction to imperativism. Some have argued that pains have indicative content, just as intentionalists have always said, but a content closely related to imperatives. In the case of the ingrown nail, pain might represent something like the goodness or the fittingness of protecting your nail (Bain, 2013; Helm, 2002). This objection is of interest both because people have raised it as an objection to imperativism, and also because some authors (including David Bain) have independently defended versions of these so-called evaluativist accounts of pain.

An adequate evaluativist theory would be troubling for the imperativist. If the evaluativist is right, suitably phrased indicatives can do whatever imperatives can do. If so, sticking to indicatives might win out as the suitably conservative, time-tested, preferable solution. Conversely, if the informational content of pain turns out to be predominantly imperative, evaluative formulations are just a different and misleading way to gloss what is fundamentally imperative content. Our fleshed-out account of content allows us to defend the latter sort of response. 
Section 2 briefly introduces the Lewis-Skyrms framework. Section 3 presents our model, and shows how and in what measure inflammatory pain is imperative. Finally, section 4 discusses some possible responses on behalf of traditional (indicativist) representationalism.

\section{Sender-Receiver Games}

In a signaling game (Lewis, 1969; Skyrms, 2010), the world can be in one of a set $S$ of jointly exhaustive and mutually exclusive states. A sender is able to observe which state the world is in. They then use a sender's rule to choose one of a set $M$ of messages (also, interchangeably, signals) to send to a receiver. Upon receipt of the message, the receiver follows the receiver's rule to do one of a set $\mathrm{A}$ of acts. There is a payoff associated to each state-act tuple (see Table 1).

\begin{tabular}{llll}
\hline & $A_{1}$ & $A_{2}$ & $A_{3}$ \\
\hline$S_{1}$ & 1,1 & 0,0 & 0,0 \\
$S_{2}$ & 0,0 & 1,1 & 0,0 \\
$S_{3}$ & 0,0 & 0,0 & 1,1 \\
\hline
\end{tabular}

Table 1: Sender and receiver payoff matrices. At any cell, $c_{i j}$, the first number is the payoff for the sender of the combination of state $S_{i}$ and act $A_{j}$. The second number is the payoff for the receiver.

In a game with $n$ states, $m$ messages, and $o$ acts, a sender's rule can be characterized by an $n \times m$ matrix, where each row is a probability distribution over $M$, indicating the probabilities with which the sender will send each message in the state corresponding to that row. Table 2 provides an example of a sender's rule for a game with three states and three messages. A receiver's rule 
is characterized by a similar, $m \times o$ matrix in which each row gives a probability vector over $A$ indicating the probabilities with which the receiver will do each act upon reception of the message corresponding to that row.

\begin{tabular}{llll}
\hline & $M_{1}$ & $M_{2}$ & $M_{3}$ \\
\hline$S_{1}$ & 0 & $\frac{1}{2}$ & $\frac{1}{2}$ \\
$S_{2}$ & 1 & 0 & 0 \\
$S_{3}$ & $\frac{1}{3}$ & $\frac{1}{3}$ & $\frac{1}{3}$ \\
\hline
\end{tabular}

Table 2: A sender's rule.

We will talk of sender-receiver configurations to refer to ordered tuples of: a sender payoff matrix, a receiver payoff matrix, a vector of unconditional state probabilities, a sender's rule and a receiver's rule. Some sender-receiver configurations are noteworthy; for example, a Nash equilibrium is a senderreceiver configuration such that neither sender nor receiver can increase their average payoff by changing their rule unilaterally. Other configurations might be the result of the evolution of a population of senders and a population of receivers following, e.g., the replicator dynamics.

We can calculate the informational content (Skyrms, 2010, ch. 3) that messages carry about states in a sender-receiver configuration as follows. Suppose again we are dealing with a game with $m$ states, $n$ messages and $o$ acts. The (unconditional) entropy of states is given by

$$
H(S)=\sum_{1 \leq i \leq m} \operatorname{Pr}\left(S_{i}\right) \log _{2}\left(\operatorname{Pr}\left(S_{i}\right)\right)
$$

And the entropy of states conditional on messages is given by 


$$
H(S \mid M)=\sum_{1 \leq i \leq n} \operatorname{Pr}\left(M_{i}\right) H\left(S \mid M=M_{i}\right)
$$

where $\operatorname{Pr}\left(S_{i}\right)$ is the unconditional probability of state $S_{i}$. One mathematical expression of the information that messages carry about states is the mutual information between states and messages:

$$
I(S ; M)=H(S)-H(S \mid M)
$$

Analogously, we can calculate the information that messages carry about acts as the mutual information between them:

$$
I(A ; M)=H(A)-H(A \mid M)
$$

The fact that we can describe two informational contents (about states and about acts) is often offered as a suitable precursor to the distinction between imperatives and indicatives. Thus, e.g., Kevin Zollman suggests that "in order to account for the distinction between directives and assertions, we must find ... a game where (in equilibrium) the signal carries information about the state and not the act or, alternatively, about the act and not the state." (Zollman, 2011, p. 162); similarly, Simon Huttegger claims that "the emphasis in the meaning of imperatives is to motivate behavior while the emphasis in the meaning of indicatives is to indicate some state of the world." (Huttegger, 2007, p. 410).

In this paper we will follow these suggestions, and quantify the indicative content carried by messages in a sender-receiver configuration as the mutual information between states and messages, $I(S ; M)$. Analogously, we will use $I(A ; M)$ as a measure of imperative content: high mutual information between 
messages and states means that, as Huttegger puts it, messages indicate states of the world; high mutual information between messages and $\operatorname{acts}^{3}$ means that messages motivate receiver's behavior. ${ }^{4}$

Messages can carry perfect indicative and imperative content. Consider, for example, the sender-receiver configuration individuated by the payoff matrices in Table 1, unconditionally equiprobable states, and a sender's and receiver's rule that are both equal to the identity $3 \times 3$ matrix (that is, the sender is sending only $M_{i}$ in state $S_{i}$, and the receiver is doing only $A_{i}$ upon reception of $M_{i}$ ). In that configuration, $I(S ; M)=I(A ; M)=\log _{2} 3$, the highest possible value for a game with three states, three messages, and three acts.

But these two contents can come apart. Suppose the receiver is still responding with the $3 \times 3$ identity matrix, but the sender is following the rule in Table 3 . If so, $I(M ; A)$ is still $\log _{2} 3$ bits, but $I(M ; S)=0$. Messages in this configuration carry imperative content, but no indicative content: the receiver is paying attention to what the sender says, but what the sender says is useless as a guide to the world. Analogous examples can be constructed in which messages carry indicative, but no imperative, content.

\begin{tabular}{llll}
\hline & $M_{1}$ & $M_{2}$ & $M_{3}$ \\
\hline$S_{1}$ & $\frac{1}{3}$ & $\frac{1}{3}$ & $\frac{1}{3}$ \\
$S_{2}$ & $\frac{1}{3}$ & $\frac{1}{3}$ & $\frac{1}{3}$ \\
$S_{3}$ & $\frac{1}{3}$ & $\frac{1}{3}$ & $\frac{1}{3}$ \\
\hline
\end{tabular}

Table 3: A pooling sender's rule

We will say that, in a certain sender-receiver configuration, messages are predominantly imperative iff $I(M ; A) \gg I(M ; S)$ and predominantly indicative

\footnotetext{
${ }^{3}$ At least when messages are (partially) causally responsible for acts, as they are in the pain model we describe below.

${ }^{4}$ It is possible to quantify the indicative/imperative information that single messages carry about single states/acts. For example, Skyrn\$s (2010, p. 41) proposes that we quantify the information that message $M_{i}$ carries about state $S_{j}$ as$$
\log \frac{\operatorname{Pr}\left(S_{i} \mid M_{j}\right)}{\operatorname{Pr}\left(S_{i}\right)}
$$

and mutatis mutandis for individual acts. The weighted average of these individual contributions is the mutual information between messages and states (acts), which is what we have proposed using as a measure of the overall indicativeness and imperativalness of messages in a game.
} 
iff $I(M ; S) \gg I(M ; A)$. If messages are neither, they approximate what Millikan (1995) calls pushmi-pullyu representations - at once imperative and indicative. ${ }^{5}$

Neither of the purely indicative and purely imperative configurations we have just seen is one in which sender and receiver can be expected to spend much time in, though. They are not Nash equilibria, and in the purely imperative configuration the sender (and the receiver) would be better off if the sender was perfectly informative about the state of the world - the configuration would be pushed in the direction of perfect indicative and imperative information. The analogous purely indicative configuration would have a similar fate. ${ }^{6}$

To develop the model further, then, we turn to discussing a model of inflammatory pain. This has two advantages: it is biologically realistic, and it is one in which messages are predominantly imperative even in equilibrium.

\section{A game-theoretic model of pain}

Inflammation is an innate system of responses to injury (Ward, 2010, p. 1), that normally aids in healing. ${ }^{7}$ For our current purposes, the most important feature of inflammatory states is that "normally innocuous stimuli produce pain" (Kidd and Urban, 2001, p. 3). This so-called sensitization can be temporary; if short-lived it is called modulation, while if long-lasting modification (Woolf and Mannion, 1999). The effect of inflammation can be dramatic. The inflamed

\footnotetext{
${ }^{5}$ Assuming that they are contentful at all. Messages might also be neither predominantly imperative nor indicative via carrying no information. As pains obviously do something, we will ignore this possibility in what follows.

${ }^{6}$ That is not to say that partially pooling configurations never evolve in the game in Table 1. Huttegger et al. (2010, p. 183) report that the replicator dynamics in discrete time takes senders and receiver to a partial pooling equilibrium $4.7 \%$ of the time. Our current point is, rather, that configurations in which there is information transfer (including the partially pooling ones reported by Huttegger and colleagues) are inaccessible, at least by the replicator dynamics, from an initial population structure in which the sender is being perfectly informative and the receiver pools perfectly, or vice versa.

${ }^{7}$ Not always, however. Severe inflammation can cause persistent tissue damage, which singles it out as an important target for treatment; see (Nathan, 2002).
} 
big toe joint in gout sufferers, for example, can be excruciatingly painful in circumstances where the very same agent has previously had no trouble: putting on shoes or even the touch of bedsheets.

We will use the pain of an ingrown nail as an example. The following is a simple model of inflammation-induced sensitization. The game is played between a certain nail bed's nociceptors and the motor cortex. There are two possible situations in which the game is played: in the presence or the absence of tissue inflammation. In each of these situations, we will assume that nociceptors are able to perceive (without error) which member of the following set the world is in:

$S_{1}$ : The nail is undergoing severe mechanical stimulation

$S_{2}$ : The nail is undergoing mild mechanical stimulation

$S_{3}$ : The nail is undergoing no mechanical stimulation

On the other hand, the motor cortex can undertake any one of the following four actions:

$A_{1}$ : Protect the nail (very high priority)

$A_{2}$ : Protect the nail (high priority)

$A_{3}$ : Protect the nail (low priority)

$A_{4}$ : Remain at ease

Finally, we assume that the sender has four available messages: $M_{1}$ through $M_{4}$.

There are three "protect the nail" actions: very high, high and low priority. One way to cash out the difference between them is by thinking of which other 
actions one will postpone in order to carry out these ones: the very high priority version will promote itself to the top of the agent's to-do list. The low priority version, not so much. For more on priorities see our (Klein and Martínez, forthcoming).

The payoff matrices for the game sender and receiver are playing are as in Table 4 (only one payoff in each cell: both players collect the same payoff in every situation):

\begin{tabular}{|c|c|c|c|c|c|c|c|c|}
\hline & \multicolumn{4}{|c|}{ Normal } & \multicolumn{4}{|c|}{ Inflammation } \\
\hline & $A_{1}$ & $A_{2}$ & $A_{3}$ & $A_{4}$ & $A_{1}$ & $A_{2}$ & $A_{3}$ & $A_{4}$ \\
\hline$S_{1}$ & 0 & 1 & 0 & -1 & 1 & 0 & -1 & -2 \\
\hline$S_{2}$ & -1 & 0 & 1 & 0 & 0 & 1 & 0 & -1 \\
\hline$S_{3}$ & -2 & -1 & 0 & 1 & -1 & 0 & 1 & 0 \\
\hline
\end{tabular}

Table 4: The pain game

This payoff matrix is constructed as follows: in the absence of inflammation, the best action in the presence of mild mechanical stimulation is low-priority protection; in the presence of severe mechanical stimulation it is high-priority protection; and when there is no stimulation one should remain at ease. Suboptimal acts are penalized by how far they are from the optimum - minus one point if once removed, minus two if twice. In the presence of inflammation, protection is prioritized: the optimal act (i.e., the diagonal of ones in the matrix) has shifted one slot to the left.

In this game, one of the best-paying Nash equilibria ${ }^{8}$ is given by the combi-

\footnotetext{
${ }^{8}$ In the sense that there are other equilibria with the same expected payoff, but none with a better one. Whenever we speak of "a best-paying equilibrium" throughout the paper, this is what we mean.
} 
nation of sender's and receiver's rules in Tables 5 and 6 :

\begin{tabular}{cccccc||cccc}
\hline & \multicolumn{4}{c}{ Normal } & \multicolumn{5}{c}{ Inflammation } \\
\hline & $M_{1}$ & $M_{2}$ & $M_{3}$ & $M_{4}$ & $M_{1}$ & $M_{2}$ & $M_{3}$ & $M_{4}$ \\
\hline$S_{1}$ & 0 & 1 & 0 & 0 & $\|$ & 1 & 0 & 0 & 0 \\
$S_{2}$ & 0 & 0 & 1 & 0 & $\|$ & 0 & 1 & 0 & 0 \\
$S_{3}$ & 0 & 0 & 0 & 1 & $\|$ & 0 & 0 & 1 & 0 \\
\hline
\end{tabular}

Table 5: The sender's rule

\begin{tabular}{lllll}
\hline & $A_{1}$ & $A_{2}$ & $A_{3}$ & $A_{4}$ \\
\hline$M_{1}$ & 1 & 0 & 0 & 0 \\
$M_{2}$ & 0 & 1 & 0 & 0 \\
$M_{3}$ & 0 & 0 & 1 & 0 \\
$M_{4}$ & 0 & 0 & 0 & 1 \\
\hline
\end{tabular}

Table 6: The receiver's rule

Supposing all three states are equiprobable, Fig. 1 shows the mutual information between states and messages, $I(S ; M)$, and between acts and messages, $I(A ; M)$, as a function of the probability of inflammation. As the figure shows, for probabilities of inflammation strictly between 0 and 1 , with the exception of those very close to these extremes, messages in the model are predominantly imperative, maximally so when the probability of inflammation is one half. A reasonably good English paraphrase of the content of these messages, then, is:

$M_{1}$ : Protect your nail (with very high priority)

$M_{2}$ : Protect your nail (with high priority)

$M_{3}:$ Protect your nail (with low priority) 


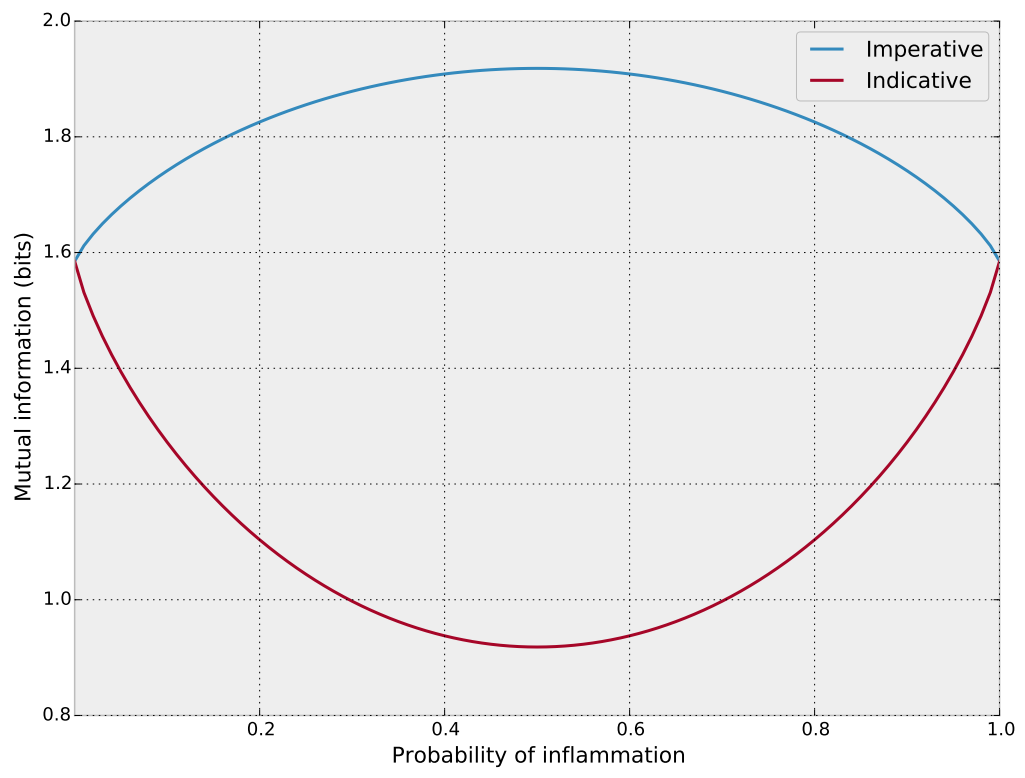

Figure 1: Amounts of imperative and indicative information carried by messages in the pain game, as a function of the probability of inflammation. 
$M_{4}:$ Don't do anything

Why do messages behave in this way in equilibrium? In a nutshell, the receiver is unaware of whether the pain message originated during an inflammatory process or not, and simply maps each message onto the relevant action. On the other hand, the sender has to choose which message to send depending on the presence of inflammation. Solely by looking at a message, then, one can be certain of what act will follow, but not of what state originated it; hence the imperativalness. ${ }^{9}$

The assumption that senders see, and receivers do not see, whether there is inflammation is empirically well motivated. Sensitization involves "an increase in the excitability of the nociceptor terminal membrane ... on exposure of the terminal to sensitizing agents ... [which] include inflammatory mediators" (Woolf and Mannion, 1999, p. 1766). Sensitization is largely a peripheral process, occurring primarily at the nociceptor and the spinal gate (Melzack and Wall, 1965). That is, the nociceptor 'sees' the inflammation (meaning: its firing profile is affected by the presence of inflammation), but the receiver only 'sees' the firing.

\section{Indicative Reconstructions}

Someone who wishes to deny that the signals exchanged in the pain game are predominantly imperative has three moves available:

\subsection{Rearranging the Game}

The first possible response is to advocate a different partition of the set of possible world states. For example, in the pain game we could recognize the

\footnotetext{
${ }^{9}$ More precisely, messages effect a partition of the set of posslble acts, but not of the set of
} possible states. 
following states.

$S_{1}^{*}$ : The nail is undergoing severe mechanical stimulation in the absence of inflammation, or mild mechanical stimulation in the presence of inflammation.

$S_{2}^{*}$ : The nail is undergoing mild mechanical stimulation in the absence of inflammation, or no mechanical stimulation in the presence of inflammation.

$S_{3}^{*}$ : The nail is undergoing no mechanical stimulation in the absence of inflammation.

If we recalculate the payoff matrices with this new set of states, all bestpaying Nash equilibria turn out to be signaling systems. The signals exchanged in those configuration are no longer predominantly imperative, and carry perfect information about both states and acts.

How compelling this regrouping is will depend, of course, on how satisfying you find brute disjunctions. We dislike them. On the one hand, if this is a legitimate move then the imperative/indicative distinction entirely collapses (at least within the Lewis-Skyrms framework). As any heterogenous set of states can be bundled via disjunction into a single 'state,' the same strategy could be applied to any imperative statement. The distinction between imperatives and indicatives is worth keeping, and so this sort of move must be illegitimate absent further justification for the disjunction.

On the other hand, brute disjunctions are theoretically unsatisfying. They suggest missed generalizations (Fodor, 1997, p. 158). Ideally, we would like disjunctions like $S_{1}^{*}$ to be representable in some way that picks out a single property common to each of the disjuncts. What might that be, though? The only obvious common property is that the biologically appropriate response to 
each situation is for the nail to be protected with the requisite degree of urgency. Put that way, however, it is clear that it is more useful to think of the signal in terms of the act it causes than in terms of the state that causes it, precisely as happens with imperatives. So either one is stuck with a theoretically unsatisfying disjunction (in which case our initial characterization of the game is preferable), or else one recasts the disjunction in a way that makes clear that it is the action, not the state of the world, that really matters.

Finally, there are independent, compelling theoretical reasons to separate mechanical stimulation and inflammation. Consider the assumptions that both sets of states (the $S_{i}$ on the one hand, the $S_{i}^{*}$ on the other) are making: the way of carving state space according to the $S_{i}$ is one in which the presence or absence of inflammation functions as a background condition, against which episodes of mechanical stimulation play out. The $S_{i}^{*}$ on the other hand present a world of states made up of combinations of inflammation or lack of it, plus mechanical stimulation or lack of it. Inflammation and mechanical stimulation should not be run together. Their temporal profile and etiology are very different: inflammation is often chronic, and can last for months or years, while mechanical stimulation is usually short-lived. Mechanical stimulation comes most often from outside, while inflammation is an endogenous process. There are thus good theoretical reasons to distinguish the two influences, even if the organism does not. The $S_{i}^{*}$ partition is hard to defend, even leaving disjunction aside.

\subsection{Recarving the Game}

Our model is an idealization. Real pain signals are more complicated. Whether those complications affect the validity of our model is an important question. One might object that actual pain signals are more finely individuated than we've allowed. That is, suppose one had a larger repertoire of messages such 
that it turns out that different ones are sent in the presence and the absence of inflammation—see Table 7.

\begin{tabular}{|c|c|c|c|c|c|c|}
\hline & \multicolumn{3}{|c|}{ Normal } & \multicolumn{3}{|c|}{ Inflammation } \\
\hline & $M_{1}$ & $\overline{M_{2}}$ & $M_{3}$ & $M_{4}$ & $M_{5}$ & $\overline{M_{6}}$ \\
\hline$S_{1}$ & 1 & 0 & 0 & 1 & 0 & 0 \\
\hline$S_{2}$ & 0 & 1 & 0 & 0 & 1 & 0 \\
\hline$S_{3}$ & 0 & 0 & 1 & 0 & 0 & 1 \\
\hline
\end{tabular}

Table 7: The recarved sender's rule

\begin{tabular}{lllll}
\hline & $A_{1}$ & $A_{2}$ & $A_{3}$ & $A_{4}$ \\
\hline$M_{1}$ & 0 & 1 & 0 & 0 \\
$M_{2}$ & 0 & 0 & 1 & 0 \\
$M_{3}$ & 0 & 0 & 0 & 1 \\
$M_{4}$ & 1 & 0 & 0 & 0 \\
$M_{5}$ & 0 & 1 & 0 & 0 \\
$M_{6}$ & 0 & 0 & 1 & 0 \\
\hline
\end{tabular}

Table 8: The recarved receiver's rule

This sender's rule, together with the receiver's rule in Table 8 , constitutes a best-paying Nash equilibria in which messages are perfectly informative about both states and acts. Imperativalness is lost again. It is just that the set of messages is more fine-grained than our model would suggest.

This is not an implausible move. Pains do differ from one another. Most importantly, pains differ in felt quality: they can be burning, stabbing, shooting, and so on. Perhaps those differences are sufficient to ground the sort of move that the expanded table was meant to capture. We take this to be an empirical 
question. We also think that a closer look at the two places where you might hope to find evidence for a fine-grained view_-peripheral physiology and pain phenomenology - both weigh against this move.

\subsubsection{Peripheral Physiology}

There is an old view of peripheral pain physiology which lingers on in popular presentations, on which there are specific 'pain receptors' for specific types of bodily insult. This view has its roots in Johannes Müller's doctrine of specific nerve energies, was elaborated by Max von Frey's theory of the cutaneous senses, and found its most sophisticated expression in mid-20th-century physiology which tried to link specific receptor-types or fiber-types to distinct qualities of pain. $^{10}$

These so-called specificity theories fell out of favor by the late twentieth century. On the one hand, many receptor types relevant to pain were shown to respond to a wide variety of stimuli. Noordenbos hypothesized that it is the pattern of firing that matters, not the receptors at the initial location. Hence, Noordenbos says, "pain may arise from virtually any type of stimulus or may be the result of afferent patterns which may travel via any available pathway" (quoted in Bakan, 1968, p. 63). Melzack and Wall's development of the Gate Control theory also emphasized the importance of temporal patterning of responses as well as top-down modulation of spinal circuits (Melzack and Wall, 1965). This means that the same afferent pattern can have very different effects depending on the condition of the central gate. This is one of the primary mechanisms for sensitization in inflammatory pain.

The complexity of peripheral response means that one ought not expect

\footnotetext{
${ }^{10}$ For historical presentations, we rely on chapter 8 of Melzack and Wall (1996). For an updated presentation see Perl (2007).
} 
differentiation among pain qualities based on simple properties of peripheral receptors. And indeed, this appears to be the case. Wall and McMahon (1985), reviewing evidence from microneurography studies that stimulated peripheral fibers, concluded that there is no simple relationship between peripheral activity and pain quality. Most importantly for our argument, stimulating very different fibers and receptors by a variety of means produced identical sensations (Wall and McMahon (1985); see also Melzack and Wall (1996) p. 87-88).

While subsequent physiological work has led to a partial revival of the specificity theory (Perl, 2007), that has mostly focused on the presence of 'pure' nociceptors and specialized pathways leading from the spinal cord. One must distinguish the proposition that the periphery contains specialized fibers from the psychological claim that these fibers have a neat mapping to distinct pain qualities. The revolt against specificity was against psychological specificity, and the evidence continues to weigh against specificity in this sense (Melzack and Wall, 1996, p. 155).

Without psychological specificity, there is no sense in which peripheral firing can be used to make fine distinctions among pains. So the recarving strategy does not receive empirical support from peripheral physiology.

\subsubsection{Pain Phenomenlogy}

Another common suggestion is that some sensory qualities correspond to particular types of injury. So, for example, one might think that burning pains represent burns, stabbing pains represent stabs, and so on. This would again give a basis for making fine-grained distinctions between pains, since presumably each of these types of pain would demand a different sort of action. Further, it is entirely a psychological thesis, and could be true regardless of peripheral 
complexities. ${ }^{11}$

This claim again appears to be empirically false. Pain descriptors do not really seem to correlate with the type of damage that descriptors would intuitively pick out. Cuts are often described as burning, stabs as sore, fractures as hot, labor as stabbing, and so on (Melzack et al., 1982; Melzack and Katz, 2006). Further, these categories often overlap: lacerations, fractures, and bruises are frequently described as tender, fractures and bruises as hot, and so on (Melzack et al., 1982, Table IV). ${ }^{12}$

Of course, none of this rules out a more specific role for pain quality. (Different pain qualities might, for example, correspond to different type of protective action that are appropriate to take. That would be entirely compatible with our account, because it would preserve degeneracy of states onto actions.) What it does suggest, however, is that one cannot recover a state-informative role for pain by going more fine-grained into pain's phenomenology.

\subsection{Reinterpreting the Game}

The third available move is to find a description of the imperative associated with each signal that is syntactically indicative. For example, instead of:

$M_{1}$ : Protect your nail (with high priority)

we would have

$M_{1}^{*}$ : Things are such that you should protect your nail (with high priority)

\footnotetext{
${ }^{11}$ Although, of course, only once we set aside the question of how phenomenology knows to match qualitative character to etiology, given those complexities.

${ }^{12}$ There is some evidence that MPQ descriptors can be used to discriminate between particular pain syndromes, as detailed in Katz and Melzack (1999). This work focused on pathological syndromes, however, and used sets of descriptors to make discriminations among pathological syndromes. As such, there is little evidence that single dimensions of pain quality correspond in any neat way to the cause of pain.
} 
and mutatis mutandis for the rest of messages. There are two ways to read these indicative rephrasings. On the one hand, the result could just be read as thinly veiled imperativism. Language is complicated, and imperatives can be expressed by syntactically indicative sentences. To say "Perhaps you ought to close the door" is, in the right circumstances, to say the very same thing as "Close the door!" We'll call this route, by way of dismissing it, British Imperativism: phrasing imperatives more politely does not make them any less imperatival.

The other reading would take seriously terms like "the right thing" (or "ought," or "is bad," or other similar possibilities). The rephrasings would be syntactically indicative because they are meant to indicate something about the world: the goodness or fittingness or rightness of certain actions. Treatments of pain such as Bain's (2013) evaluativism, on which pains depend on a representation of a disturbance as bad, are very close to this second route. The recommended content attribution to pain experiences ("this (actual/probable) tissue damage is bad for you") is not far from an outright recommendation to deal with and fix the tissue damage in question. But perhaps such a recommendation can stop short of an actual imperative, while remaining rationally motivating.

Bain argues that the reliance on indicatives helps the evaluativist "make sense ... of unpleasant pains' status as reasons" (2013, p. S82). This is so, among other things and very roughly, because reasons should be able to function as meaningful substitutions of $p$ in the schema $\ulcorner I \phi ' d$ because $\mathrm{p}\urcorner$. Indicatives, not imperatives are the adequate candidates for that role. (This is our gloss, not Bain's formulation.)

We think that the evaluativist strategy is a more general instance of what has been called the "Guise of the Good" strategy in moral psychology (Velleman, 1992). The guise of the good thesis says, very roughly, that no one can be motivated to $\phi$ without thinking of $\phi$-ing as good. Thinking of $\phi$-ing as good is 
supposed to be what separates motivation from mere compulsion; equivalently, it is what gives proper motivational states their reason-conferring force. This is one reason, we suspect, why Bain and others are attracted to evaluativism: because they think there is a basic link between pains and the goodness (badness) of particular states.

Put this way, however, we think that evaluativism falls prey to the same objections that are ordinarily levelled against the guise of the good thesis. Mark Schroeder (2008) notes that the guise of the good thesis really comes in a strong and a weak variety. The strong variety says that motivational states must represent some action as good: that is, goodness must be part of the content itself. That is what evaluativism requires, and what we deny. For if evaluativism requires that actions must be represented as good by pain, it is difficult to see how babies and animals can have the requisite concepts to have pains (as they surely do). So the strong reading seems altogether too strong a requirement for such a basic state like pain.

The weak variety of the guise of the good thesis claims only that motivational states 'aim at' the good: that is, that the good is the formal object of states like desire (2008). On this weaker sense, motivational states bear the same relationship to the good as indicative states bear to the truth. Saying that "Grass is green' is not to say anything about truth as such, though of course it is part of the aim of assertions to say true things.

This much weaker sense of the thesis, however, is entirely compatible with imperativism. It says only that imperatives aim at the good, in the sense that a system of imperatives is, more or less, good-promoting if followed. On that notion of good-promoting, we claim, imperatives often provide adequate (good, rational) grounds for action. One might ground the reason-giving relation in several different ways. It might be, as Bain suggests, because our bodies 
possess a species of epistemic authority (Bain, 2011). The distinction made by Hamblin (1987) between willful and non-willful imperatives is relevant here: non-willful imperatives (instructions, advices, recommendations, and the like) are issued with the interest of the addressee in mind, and the issuer incurs a tacit commitment to backing up the imperative with the relevant epistemic credentials. Being at the receiving end of a non-willful imperative will often provide adequate grounds for action. See (Martínez, 2015) for an imperativist treatment of the reason-giving role of pain along these lines. Alternatively, it might be, as (Klein, 2015) suggests, that we treat the body as a kind of minimal practical authority. Other relationships are possible. The point is simply that states can be motivating and reason-giving without explicitly representing their objects as good. That is all the imperativist needs to satisfy the plausible intuition behind the weak form of the guise of the good thesis.

A similar point has been made in the literature on imperatives in senderreceiver games. Recall from our previous discussion that the main divide between indicative and imperative signals lies on what it is that the signal constrains the most: world states or receiver acts. If the sender believes that a certain piece of information about the world might be useful for the receiver (might figure as a premise in one of the receiver's exercises of practical reasoning, say) they might choose to send a signal with that information. The receiver might then use this information for their own, as yet unspecified goals. This signal is indicative, and might provide the receiver with a justifying reason for an action conducive to some of those goals. On the other hand, the sender might think that they already know what the receiver should do-for example, they might see that a piano is dangerously hanging from a thin rope right above the receiver's head, and thereby issue an imperative signal (step aside!) rather than wait for the receiver to waste precious seconds working it out for himself. 
That imperative will typically also provide a justifying reason for stepping aside. Compare Huttegger (2007) and Lewis (1969): what distinguishes indicatives and imperatives is who deliberates: the receiver for indicatives; the sender for imperatives. But who deliberates should not bear on the status of a message as reason-giving. If messages can give reasons at all, then, imperatives can give reasons.

The advantage of imperativism is not simply that certain kinds of sensory states might be described as if they were something like imperatives. Loose analogies are good for motivating imperativism. But imperative content is useful because it links into a broader story about what content might be and how it might be naturalized. We've shown that imperative content is, in an important sense, relatively easy to generate. It is one pole along a spectrum of different sender-receiver strategies. It is no more odd, considered this way, than indicative content. Sterelny has argued that internal representations are biologically important because they are "decoupled" from particular actions. That lets the same representation be used in a variety of different circumstances (Sterelny, 2003). We have argued that imperatives play a structurally complimentary role: they are 'decoupled', if you like, from states of the world. Imperatives thus allow many disparate states of the world to result in the same adaptive action. Neither imperatives nor indicatives are more primitive. Both play an ineliminable role in complex adaptive action.

\section{Acknowledgements}

Financial support for this work was provided by the DGI, Spanish Government, research project FFI2011-26853 (Martínez); Consolider-Ingenio project CSD200900056 (Martínez); a Macquarie University Faculty Research Travel Scheme Grant 
(Klein); and Australian Research Council Grant FT140100422 (Klein)

We would like to thank Murat Aydede, David Bain, Matt Fulkerson, the audience of the invited symposium "Painful Pains, Yummy Tastes, Stinky Smells: Sensory Affect" at the 2014 meeting of the APA Pacific in San Diego, and two anonymous referees for comments and suggestions on an earlier draft.

\section{References}

Bjarke Abrahamsen, Jing Zhao, Curtis O Asante, Cruz Miguel Cendan, Steve Marsh, Juan Pedro Martinez-Barbera, Mohammed A Nassar, Anthony H Dickenson, and John N Wood. The cell and molecular basis of mechanical, cold, and inflammatory pain. Science, 321(5889):702-705, 2008.

M Aydede. The Main Difficulty With Pain. In M Aydede, editor, Pain: New Essays on Its Nature and the Methodology of ts Study, pages 123-136. The MIT Press. Bradford Books, 2006.

David Bain. The imperative view of pain. Journal of Consciousness Studies, 18 (9-10):164-85, 2011.

David Bain. What makes pains unpleasant? Philosophical Studies, 166:S69-S89, 2013.

David Bakan. Disease, pain, and sacrifice: Toward a psychology of suffering. University of Chicago Press, Chicago, 1968.

N Block. Bodily Sensations as an Obstacle for Representationism. In M Aydede, editor, Pain: New Essays on Its Nature and the Methodology of ts Study, pages 137-142. The MIT Press. Bradford Books, 2006. 
D Chalmers. The Conscious Mind: In Search of a Fundamental Theory. Oxford University Press, 1996.

Fred Dretske. Naturalizing the Mind. The MIT Press, 1997.

J Fodor. A Theory of Content and Other Essays. The MIT Press, 1990.

Jerry Fodor. Special sciences: Still autonomous after all these years. Philosophical perspectives: Mind, Causation, and World, 11:149-163, 1997.

C.L. Hamblin. Imperatives. Basil Blackwell, Oxford, 1987.

B.W. Helm. Felt evaluations: A theory of pleasure and pain. American Philosophical Quarterly, 39(1):13-30, 2002.

S. M. Huttegger. Evolutionary explanations of indicatives and imperatives. Erkenntnis, 66:409-436, 2007.

S. M. Huttegger, Brian Skyrms, Rory Smead, and Kevin Zollman. Evolutionary dynamics of lewis signaling games: Signaling systems vs. partial pooling. Synthese, 172:177-191, 2010.

Joel Katz and Ronald Melzack. Measurement of pain. Surgical Clinics of North America, 79(2):231-252, 1999.

BL Kidd and LA Urban. Mechanisms of inflammatory pain. British Journal of Anaesthesia, 87(1):3-11, 2001.

Colin Klein. An imperative theory of pain. The Journal of Philosophy, 104: 517-32, 2007.

Colin Klein. What the Body Commands: The Imperative Theory of Pain. MIT Press, 2015. 
Colin Klein and Manolo Martínez. Imperativism and degrees of pain. In Michael Brady and David Bain, editors, The Nature of Pain: Hedonic Tone, Motivation, and Non-Human Animals. forthcoming.

David Lewis. Convention. Cambridge: Harvard University Press, 1969.

Manolo Martínez. Imperative content and the painfulness of pain. Phenomenology and the Cognitive Sciences, 10(1):67-90, 2011.

Manolo Martínez. Pains as reasons. Philosophical Studies, 172(9):2261-2274, 2015.

Mohan Matthen. Seeing, Doing and Knowing. Oxford University Press, 2005.

Colin McGinn. Can we solve the mind-body problem? Mind, pages 349-366, 1989.

R. Melzack and P.D. Wall. Pain mechanisms: a new theory. Science, 150(699): 971-979, 1965.

R. Melzack and P.D. Wall. The challenge of pain. Penguin, New York, 1996.

R. Melzack, P.D. Wall, and T.C. Ty. Acute pain in an emergency clinic: Latency of onset and descriptor patterns related to different injuries. Pain, 14(1):33-43, 1982.

Ronald Melzack and Joel Katz. Pain assessment in adult patients. In Stephen B McMahon and Martin Koltzenburg, editors, Wall and Melzack's Textbook of Pain, pages 291-304. Elsevier, London, 5th edition, 2006.

R Millikan. Language, Thought and Other Biological Categories. The MIT Press, 1984.

R Millikan. Pushmi-ullyu Representations. Philosophical Perspectives, 9, AI, Connectionism, and Philosophical Psychology:185-200, 1995. 
Carl Nathan. Points of control in inflammation. Nature, 420 (6917):846-852, December 2002. ISSN 0028-0836. URL http://dx.doi.org/10.1038/nature01320.

David Papineau. Reality and Representation. Basil Blackwell, 1987.

Edward R Perl. Ideas about pain, a historical view. Nature Reviews Neuroscience, 8(1):71-80, 2007.

Mark Schroeder. How does the good appear to us? Social Theory and Practice, 34(1):119-130, 2008.

Brian Skyrms. Signals: Evolution, Learning 83 Information. New York: Oxford University Press, 2010.

Kim Sterelny. Thought in a hostile world: The evolution of human cognition. Blackwell Publishers, Malden, Massachusetts, 2003.

M Tye. Ten Problems of Consciousness: A Representational Theory of the Phenomenal Mind. The MIT Press. Bradford Books, 1995.

J David Velleman. The guise of the good. Nous, pages 3-26, 1992.

P.D. Wall and S.B. McMahon. Microneuronography and its relation to perceived sensation. A critical review. Pain, 21:209-229, 1985.

Peter A Ward. Acute and chronic inflammation. Fundamentals of Inflammation, pages 1-16, 2010.

Clifford J Woolf and Richard J Mannion. Neuropathic pain: aetiology, symptoms, mechanisms, and management. The Lancet, 353(9168):1959-1964, 1999.

Kevin Zollman. Separating directives and assertions. The Journal of Philosophy, 11:158-169, 2011. 